\title{
Article
}

\section{The 1 $\beta$-Hydroxy-Deoxycholic Acid to Deoxycholic Acid Urinary Metabolic Ratio: Toward a Phenotyping of CYP3A Using an Endogenous Marker?}

\author{
Gaëlle Magliocco 1,2 ${ }^{\mathbb{D}}$, Jules Desmeules ${ }^{1,2,3,4}$, Marija Bosilkovska ${ }^{1,2}$, Aurélien Thomas ${ }^{3,5,6}$ \\ and Youssef Daali $1,2,3,4, *$ (iD
}

1 Division of Clinical Pharmacology and Toxicology, Geneva University Hospitals, 1205 Geneva, Switzerland; gaelle.magliocco@unige.ch (G.M.); jules.desmeules@hcuge.ch (J.D.); marija.bosilkovska@hcuge.ch (M.B.)

2 Institute of Pharmaceutical Sciences of Western Switzerland, University of Geneva, 1206 Geneva, Switzerland

3 Swiss Center for Applied Human Toxicology, 1205 Geneva, Switzerland; aurelien.thomas@chuv.ch

4 Faculty of Medicine, University of Geneva, 1206 Geneva, Switzerland

5 Forensic Toxicology and Chemistry Unit, CURML, 1000 Lausanne University Hospital,

Geneva University Hospitals, Lausanne, 1205 Geneva, Switzerland

6 Faculty Unit of Toxicology, CURML, Faculty of Biology and Medicine, University of Lausanne, 1000 Lausanne, Switzerland

* Correspondence: youssef.daali@hcuge.ch

Citation: Magliocco, G.; Desmeules, J.; Bosilkovska, M.; Thomas, A.; Daali, Y. The $1 \beta$-Hydroxy-Deoxycholic Acid to Deoxycholic Acid Urinary Metabolic Ratio: Toward a Phenotyping of CYP3A Using an Endogenous Marker? J. Pers. Med. 2021, 11, 150. https://doi.org/ 10.3390/jpm11020150

Academic Editor: Kentaro Inamura

Received: 15 January 2021

Accepted: 16 February 2021

Published: 20 February 2021

Publisher's Note: MDPI stays neutral with regard to jurisdictional claims in published maps and institutional affiliations.

Copyright: (c) 2021 by the authors. Licensee MDPI, Basel, Switzerland. This article is an open access article distributed under the terms and conditions of the Creative Commons Attribution (CC BY) license (https:// creativecommons.org/licenses/by/ $4.0 /)$.
Abstract: In this study, we assessed the potential use of the $1 \beta$-hydroxy-deoxycholic acid $(1 \beta-\mathrm{OH}$ DCA) to deoxycholic acid (DCA) urinary metabolic ratio (UMR) as a CYP3A metric in ten male healthy volunteers. Midazolam (MDZ) $1 \mathrm{mg}$ was administered orally at three sessions: alone (control session), after pre-treatment with fluvoxamine $50 \mathrm{mg}$ (12 $\mathrm{h}$ and $2 \mathrm{~h}$ prior to MDZ administration), and voriconazole $400 \mathrm{mg}$ ( $2 \mathrm{~h}$ before MDZ administration) (inhibition session), and after a 7-day pre-treatment with the inducer rifampicin $600 \mathrm{mg}$ (induction session). The $1 \beta-\mathrm{OH}$-DCA/DCA UMR was measured at each session, and correlations with MDZ metrics were established. At baseline,

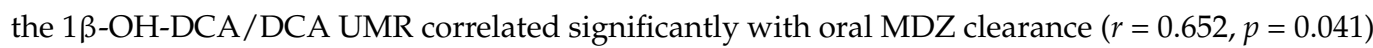
and $\mathrm{C}_{\max }(r=-0.652, p=0.041)$. In addition, the modulation of CYP3A was reflected in the $1 \beta$ $\mathrm{OH}-\mathrm{DCA} / \mathrm{DCA} \mathrm{UMR}$ after the intake of rifampicin (induction ratio $=11.4, p<0.01$ ). During the inhibition session, a non-significant $22 \%$ decrease in $1 \beta-\mathrm{OH}-\mathrm{DCA} / \mathrm{DCA}$ was observed $(p=0.275)$. This result could be explained by the short duration of CYP3A inhibitors intake fixed in our clinical trial. Additional studies, particularly involving CYP3A inhibition for a longer period and larger sample sizes, are needed to confirm the $1 \beta-\mathrm{OH}-\mathrm{DCA} / \mathrm{DCA}$ metric as a suitable CYP3A biomarker.

Keywords: CYP450; phenotyping; CYP3A; bile acid; biomarker

\section{Introduction}

Macrolide antibiotics, calcium channel blockers, immunosuppressants, benzodiazepines, and many other compounds are metabolized by the cytochrome P450 3A (CYP3A) enzymes [1]. It is estimated that approximately $30 \%$ of all marketed drugs are eliminated through this subfamily [1]. The metabolism of CYP3A substrates may be largely affected by the important pharmacokinetic variability of these enzymes' function, leading to serious therapeutic complications [2,3]. Drug-drug interactions are a major cause of variability in CYP3A activity [1]. CYP3A can be induced by ligands that bind to the nuclear receptors PXR and CAR, reducing the drug levels [4]. In contrast, a number of endogenous and exogenous compounds can also inhibit CYP3A activity, increasing the drug concentrations [5]. For example, the co-administration of CYP3A inhibitors, such as diltiazem, clarithromycin, or amiodarone, with a statin may cause rhabdomyolysis [6-8]. Genetic polymorphisms can also strongly influence CYP3A5 activity. In particular, CYP3A5*3, resulting in a non- 
functional protein, is the most frequent variant allele of CYP3A5 [3,9]. Conversely, few polymorphisms have been described for CYP3A4 [9].

To date, the standard approach for measuring CYP3A activity is phenotyping using a probe drug, taking into account the environmental component that explains most of the enzymatic variability [10].

One of the first tests developed to assess CYP3A activity was the erythromycin breath test. After the administration of $\left[{ }^{14} \mathrm{C}-\mathrm{N}\right.$-methyl]-erythromycin, the amount of exhaled ${ }^{14} \mathrm{CO} 2$ is measured, allowing prediction of CYP3A activity [11]. However, the presence of radiolabeled ${ }^{14} \mathrm{C}$ makes its use in clinical practice more complex [12]. In addition, erythromycin lacks specificity, as it is also a P-glycoprotein substrate [11].

Currently, midazolam (MDZ) is considered as the gold standard for measuring CYP3A activity. The biotransformation of MDZ into 1'-hydroxy-midazolam (OH-MDZ) is mediated exclusively through CYP3A, and MDZ is not a substrate for the main drug transporters [13]. However, phenotyping using MDZ requires the administration of an exogenous substance, which is not always well received by patients and not completely risk-free [14].

CYP3A enzymes are known to metabolize endogenous sterol lipids, including cortisol, cortisone, and dehydroepiandrosterone [15]. The metabolism of cholesterol into $4 \beta$-hydroxy-cholesterol has also been described as an endogenous CYP3A probe, but the long half-life of this latter may, to some extent, affect its use for the detection of rapid changes in CYP3A activity [16]. More recently, five acyl-carnitines derivatives have been identified as CYP3A biomarkers using untargeted metabolomics [17]. Several multivariate equations using one or more of these markers described above have been developed to optimize the prediction of CYP3A activity through MDZ clearance (CL) [15]. At baseline, an equation using $6 \beta$-hydroxy-cortisol to cortisol and $6 \beta$-hydroxy-cortisone to cortisone urinary metabolic ratios as well as sex as covariates explains $26.1 \%$ of the variation in MDZ CL [18].

The detoxification of bile acids is primarily regulated by the CYP3A4 enzyme in humans. This enzyme protects against the cytotoxicity of bile acids exacerbated at high concentration levels $[19,20]$. In fact, rifampicin, a strong inducer of CYP3A, can be used to treat some cholestatic conditions via the stimulation of the hydroxylation of bile acids [20]. Several years ago, Bodin et al. [20] observed significant amounts of $1 \beta$-hydroxy-deoxycholic acid (1 $\beta-\mathrm{OH}-\mathrm{DCA})$, a secondary bile acid, in the urine samples from five patients treated with carbamazepine compared to ten healthy volunteers. Then, it was demonstrated by Hayes et al. [21] that deoxycholic acid (DCA) is specifically metabolized into $1 \beta-\mathrm{OH}$ DCA by CYP3A4 and CYP3A7 using recombinant human CYP450 enzymes. In contrast, CYP3A5 isoenzyme seems not or poorly involved in the $1 \beta$-hydroxylation of DCA (around $10-50$ times lower) [21-23]. DCA and $1 \beta-\mathrm{OH}-\mathrm{DCA}$ can be conjugated to glycine, taurine, glucuronic acid, and sulfate in human hepatocytes. For both bile acids, the glycine conjugate appears to be the major metabolite, as reported by Hayes et al. [21]. In the study of Hayes et al. [21], they also measured the $1 \beta-\mathrm{OH}-\mathrm{DCA}$ to DCA urinary metabolic ratio (UMR) in a sample from a carbamazepine-treated patient that was 7-fold higher than that of a control sample (pooled urine from six healthy controls). The authors concluded that further studies should be conducted to evaluate the promising ability of the $1 \beta-O H-D C A / D C A$ UMR to phenotype the CYP3A4 enzyme.

Therefore, the objective of our work was to provide additional data concerning the couple $1 \beta-\mathrm{OH}-\mathrm{DCA} / \mathrm{DCA}$ in human urine. The study consisted of analyzing urine samples from ten healthy male volunteers receiving oral MDZ (as part of a phenotyping cocktail) alone, after inhibition, and after the induction of CYP3A, in order to measure the impact on the $1 \beta-\mathrm{OH}-\mathrm{DCA} / \mathrm{DCA}$ ratio and to verify the correlation with MDZ, which is the model substrate drug for CYP3A activity. 


\section{Materials and Methods}

\subsection{Study Design and Population}

Data and samples were extracted from another study involving ten healthy male volunteers, with the primary objective of evaluating whether the capillary dried blood spot sampling method was appropriate for the simultaneous phenotyping of CYP450 and P-glycoprotein using a cocktail approach. More details about the study have been described elsewhere [24].

All the subjects were non-smokers, had normal liver function tests, and were not taking any drugs that affect CYP450 activity. In addition, they were not allowed to drink grapefruit juice for at least one week before and for the duration of the clinical trial.

Figure 1 describes the study timeline for this sub-study.

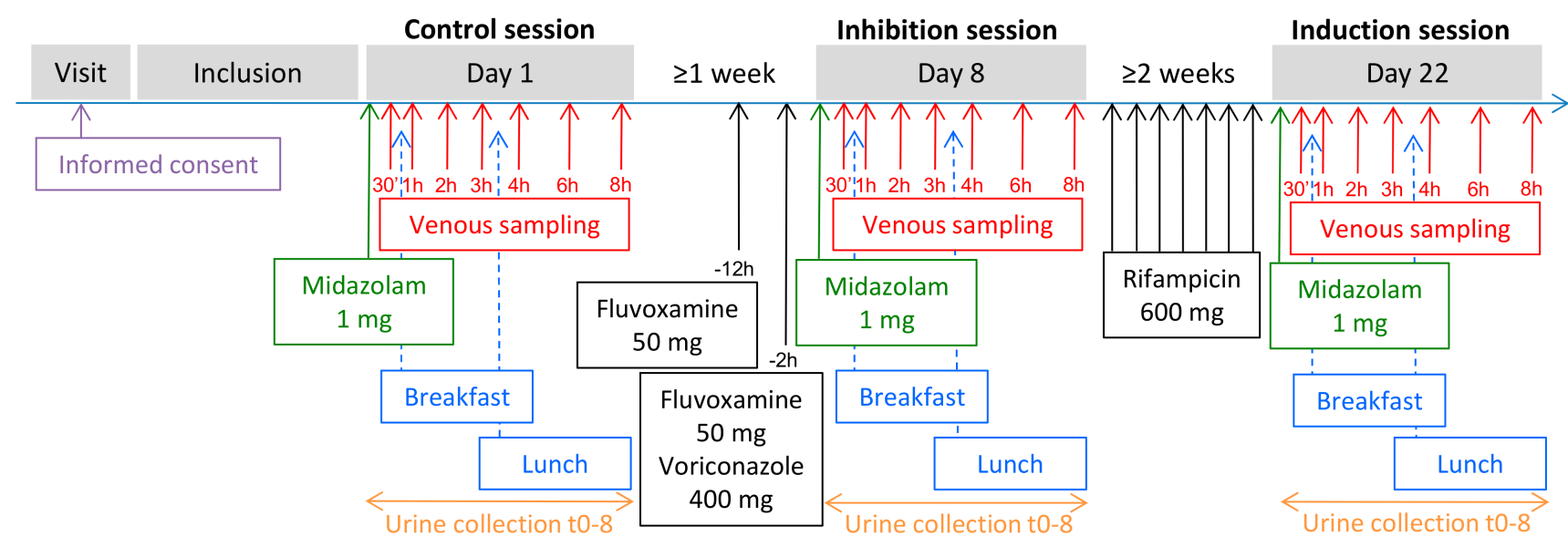

Figure 1. Study timeline. Midazolam $1 \mathrm{mg}$, as part of the Geneva cocktail, was orally administered on days 1,8 , and 22. Fluvoxamine $50 \mathrm{mg}$ was administered $12 \mathrm{~h}$ and $2 \mathrm{~h}$ before the administration of midazolam (inhibition session). Voriconazole $400 \mathrm{mg}$ was administered $2 \mathrm{~h}$ before the administration of midazolam (inhibition session). Rifampicin $600 \mathrm{mg}$ was administered once daily for seven days until the evening before the administration of midazolam (induction session).

Healthy volunteers were administered, as part of the Geneva cocktail, MDZ $1 \mathrm{mg}$ for CYP3A phenotyping at baseline (control session). During the inhibition session, participants received MDZ $1 \mathrm{mg}$ after fluvoxamine intake $(50 \mathrm{mg}$, two doses $12 \mathrm{~h}$ and $2 \mathrm{~h}$ before MDZ administration) and voriconazole intake $(400 \mathrm{mg}$, one dose $2 \mathrm{~h}$ before MDZ administration) [24]. MDZ $1 \mathrm{mg}$ was also received after a pretreatment with the inducer rifampicin (600 mg, one tablet every evening for seven days until the evening before administration of MDZ) (induction session). Urine samples were collected over $8 \mathrm{~h}$ after MDZ administration at each session. Venous blood samples $(3 \mathrm{~mL}$ ) were collected before (time 0$)$ as well as $0.5,1,2,3,4,6$, and $8 \mathrm{~h}$ after probe drug administration. Breakfast and lunch were served approximately $1 \mathrm{~h}$ and $4 \mathrm{~h}$, respectively, after the blood sampling. The trial is registered at http:/ / www.clinicaltrials.gov (NCT01731067).

\subsection{Quantification of Exogenous and Endogenous Probes}

Analyses of MDZ and OH-MDZ in plasma were performed using a single reversephase high-performance liquid chromatography coupled with tandem mass spectrometry (LC-MS/MS) method as described in the study of Bosilkosvka et al. [25].

Urinary DCA and $1 \beta-\mathrm{OH}-\mathrm{DCA}$ were quantified according to the method described by Hayes et al. [21] with some modifications. The LC-MS/MS quantification of DCA and DCA-D4 was performed using calibration standards purchased from Sigma (St. Louis, $\mathrm{MO}, \mathrm{USA}$ ), and from Expert Synthesis Solutions (London, ON, Canada) for $1 \beta-\mathrm{OH}-\mathrm{DCA}$ and $1 \beta-\mathrm{OH}-\mathrm{DCA}-\mathrm{D} 4$. To $300 \mu \mathrm{L}$ of urine samples, $2 \mu \mathrm{L}$ of the internal standards (IS) stock solution ( $3000 \mathrm{ng} / \mathrm{mL}$ DCA-D4 and $1 \beta-\mathrm{OH}-\mathrm{DCA}-\mathrm{D} 4$ in methanol) was added. Then, $225 \mu \mathrm{L}$ of $0.1 \mathrm{M}$ sodium acetate buffer ( $\mathrm{pH} 5.6$ ), $8 \mu \mathrm{L}$ of $\beta$-glucuronidase/arylsulfatase from Helix 
pomatia (Roche), and $75 \mu \mathrm{L}$ of choloylglycine hydrolase from Clostridium perfringens $(0.2 \mathrm{U} / \mu \mathrm{L})\left(\right.$ Sigma) were are also added before incubation overnight at $37^{\circ} \mathrm{C}$.

After incubation, $300 \mu \mathrm{L}$ of acetonitrile (ACN) were added, and samples were centrifuged at $4000 \times g$ for $20 \mathrm{~min}$. The supernatant was evaporated under nitrogen at a reduced volume of less than $600 \mu \mathrm{L}$. Samples were acidifed with $750 \mu \mathrm{L}$ of water with formic acid $0.1 \%$. Then, analytes extraction was performed by Solid Phase Extraction (SPE) using Oasis MAX cartridges (Waters). MAX cartridges were conditioned with methanol $(1 \mathrm{~mL})$ and equilibrated with water $(1 \mathrm{~mL})$. Samples were passed through the MAX cartridges followed by washing with $1 \mathrm{~mL}$ of water. All analytes were finally eluted by isopropanol/ACN (6:4) (1 mL). The eluates were evaporated to dryness under a stream of nitrogen and dissolved in $80 \mu \mathrm{L}$ of ACN 10\% before injection into the LC-MS/MS system. Along with the urine samples (including hydrolysis and SPE), standard solutions of DCA and $1 \beta-\mathrm{OH}-\mathrm{DCA}$ were prepared in $0.1 \mathrm{M}$ sodium acetate buffer ( $\mathrm{pH}$ 5.6) at concentrations between 0.1 and $1000 \mathrm{ng} / \mathrm{mL}$ with IS [26,27].

LC-MS/MS analyses were carried out using an Agilent 1290 Infinity series LC system from Agilent (Paolo Alto, CA, USA) coupled to a 6500 QTtrap ${ }^{\circledR}$ triple quadrupole linear ion trap mass spectrometer from $\mathrm{AB}$ Sciex equipped with an electrospray ionization (Darmstadt, Germany). Separation was performed with a Kinetex ${ }^{\circledR} \mathrm{C} 18$ column $(50 \times 2.1 \mathrm{~mm}, 2.6 \mu \mathrm{m})$ from Phenomenex (Brechbühler, Switzerland). Analyst software (version 1.6.2) was used for system control, data acquisition, and quantification. A linear gradient was applied with a mobile phase composed of (A) water containing $0.1 \%$ acetic acid and (B) ACN containing $0.1 \%$ acetic acid. Gradient elution was performed at a $500 \mu \mathrm{L} / \mathrm{min}$ flow rate as follows: $0-1.0 \mathrm{~min} 28 \% \mathrm{~B}, 1.0-4.5$ from $28 \%$ to $30 \% \mathrm{~B}, 4.5-7.5$ from $30 \%$ to $55 \% \mathrm{~B}, 7.5-7.6 \mathrm{~min}$ from $55 \%$ to $90 \%$ B, $7.6-8.6 \mathrm{~min} 90 \% \mathrm{~B}, 8.6-8.7 \mathrm{~min}$ from $90 \%$ to $28 \% \mathrm{~B}$, and $8.7-10 \mathrm{~min} 28 \%$ B. The injection volume was set at $10 \mu \mathrm{L}$. Detection of analytes was obtained in negative mode detection using multiple reaction monitoring (MRM). Most of the unconjugated bile acids, such as DCA and $1 \beta-\mathrm{OH}-\mathrm{DCA}$, do not fragment when subjected to collisioninduced dissociation. Therefore, we used a MS/MS transition without fragmentation as performed in previous studies [28-30]. Values of QTrap parameters were as follows: curtain gas $=40 \mathrm{psi}$, collision gas $=$ high, IonSpray voltage $=4500 \mathrm{~V}$, temperature $=550{ }^{\circ} \mathrm{C}$, ion source gas $1=60 \mathrm{psi}$, ion source gas $2=60 \mathrm{psi}$. The MRM transitions for each analyte and IS, and their corresponding optimum MS parameters are described below in Table 1. Accuracy of quality control samples was within $85 \%$ and $115 \%$ and both intra-day and inter-day variabilities did not exceed $15 \%$.

Table 1. LC-MS/MS settings for the analytes and their respective internal standards (IS).

\begin{tabular}{ccccc}
\hline Compound & MRM & Collision Energy (V) & Declustering Potential (V) & Cell Exit Potential (V) \\
\hline DCA & $391.2 \rightarrow 391.2$ & -20 & -160 & -17 \\
\hline DCA-D4 & $395.2 \rightarrow 395.2$ & -20 & -160 & -17 \\
\hline 1 $\beta$-OH-DCA & $407.2 \rightarrow 407.2$ & -18 & -200 & -29 \\
\hline 1 $\beta$-OH-DCA-D4 & $411.3 \rightarrow 411.3$ & -18 & -200 & -29 \\
\hline
\end{tabular}

\subsection{Statistical Analysis}

The pharmacokinetic parameters of MDZ were obtained by standard noncompartmental methods using WinNonlin version 6.2.1 (Pharsight, Mountain View, CA, USA). The following MDZ metrics were measured:

- Oral midazolam clearance (oral MDZ CL)

- $\quad 1^{\prime}$-hydroxy-midazolam $\mathrm{AUC}_{0-8}$ to midazolam $\mathrm{AUC}_{0-8}$ ratio $\left(\mathrm{AUC}_{8} \mathrm{OH}-\mathrm{MDZ} / \mathrm{AUC}_{8} \mathrm{MDZ}\right)$

- $\quad 1^{\prime}$-hydroxy-midazolam to midazolam metabolic ratio at 1 and $2 \mathrm{~h}$ (OH-MDZ/MDZ MR)

- Midazolam maximum blood concentration (MDZ $\mathrm{C}_{\max }$ ). 
Inhibition ratios were calculated as follows [31]:

$$
\begin{aligned}
& \text { Inhibition ratio }=\frac{\text { Metric }_{\text {after inhibition }}}{\text { Metric }_{\text {before inhibition }}} \text {. } \\
& \text { Induction ratio }=\frac{\text { Metric }_{\text {after induction }}}{\text { Metric }_{\text {before induction }}} \text {. }
\end{aligned}
$$

\section{Results}

\subsection{Subjects}

Ten healthy male volunteers were enrolled and completed the study. They were aged between 20 and 36 years of age (median age: 23) with a body mass index (BMI) between 19.9 and 24.4 (median BMI: 22.0) (see the research article by Bosilkovksa et al. [24] for more details).

\subsection{Exogenous and Endogenous CYP3A Phenotyping Metrics}

Oral MDZ CL decreased significantly after a dose of fluvoxamine $(50 \mathrm{mg}) 12 \mathrm{~h}$ prior to MDZ administration, followed by a second dose of fluvoxamine $(50 \mathrm{mg})$ taken concomitantly with voriconazole $(400 \mathrm{mg}) 2 \mathrm{~h}$ before MDZ administration (Figure 2).

(a)

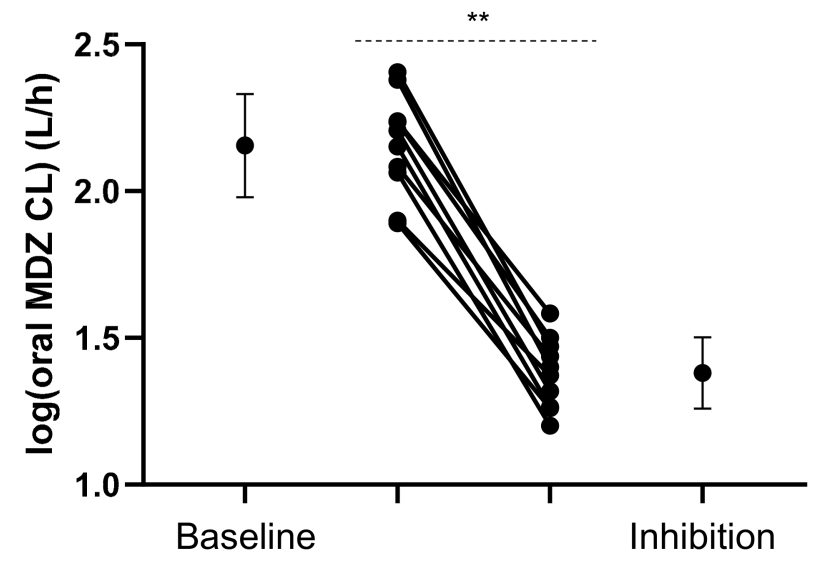

(b)

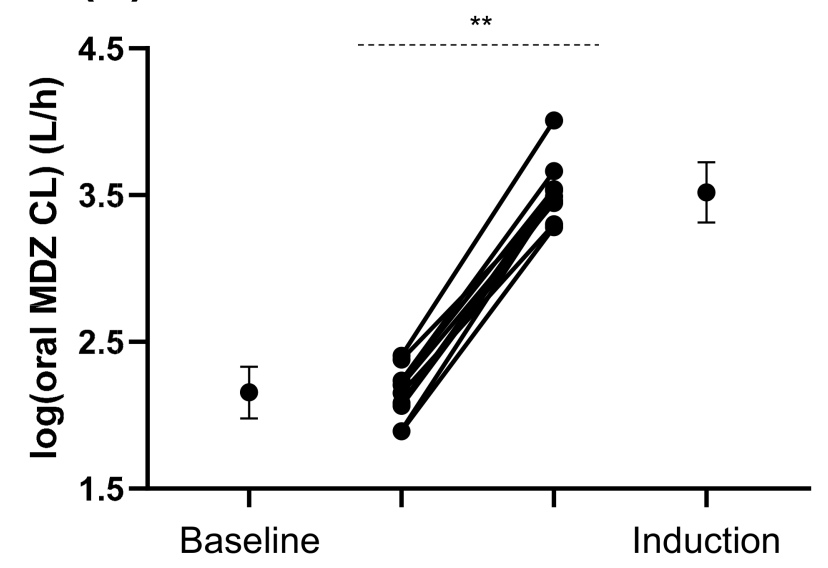

Figure 2. Oral midazolam clearance in ten mal volunteers who received $1 \mathrm{mg}$ midazolam orally at baseline and after (a) inhibition by voriconazole and fluvoxamine, and (b) induction by rifampicin. Error bars represent the standard deviations of log-transformed oral midazolam clearance and mean values are displayed with a circle. CL, clearance; MDZ, midazolam. ${ }^{* *} p<0.01$

All pharmacokinetic parameters of MDZ before and after the ingestion of inhibitors and the inducer are presented in Table 2. 
Table 2. Pharmacokinetic parameters of endogenous and exogenous probes before and after the ingestion of inhibitors and the inducer, including inhibition and induction ratios.

\begin{tabular}{|c|c|c|c|c|c|}
\hline & Baseline & Inhibition & Inhibition Ratio & Induction & Induction Ratio \\
\hline UMR1 $\beta-O H-D C A / D C A$ & $0.25(0.13-0.45)$ & $0.19(0.09-0.41)$ & $0.78(0.52-1.2)$ & $2.8(1.3-6.0)$ & $11.4^{* *}(6.3-20.7)$ \\
\hline $\begin{array}{c}\text { Urinary DCA } \\
\text { excretion }(\mu \mathrm{g} / 8 \mathrm{~h})\end{array}$ & $63.3(27.6-145.1)$ & $50.2(22.7-110.8)$ & $0.79(0.40-1.6)$ & $22.1(9.2-52.8)$ & $0.35 *(0.13-0.92)$ \\
\hline $\begin{array}{c}\text { Urinary1 } \beta \text {-OH-DCA } \\
\text { excretion }(\mu \mathrm{g} / 8 \mathrm{~h})\end{array}$ & $15.5(5.8-41.3)$ & $9.6(4.1-22.5)$ & $0.62(0.26-1.5)$ & $61.8(30.9-123.3)$ & $4.0 *(1.4-11.0)$ \\
\hline Oral MDZ CL (L/h) & $143.0(107.1-191.0)$ & $24.0(19.7-29.3)$ & $0.17^{* *}(0.13-0.22)$ & $3296(2351-4622)$ & $23.1^{* *}(17.3-30.7)$ \\
\hline $\mathrm{AUC}_{8}$ OH-MDZ/AUC 8 MDZ & $0.45(0.36-0.58)$ & $0.17(0.14-0.22)$ & $0.38^{* *}(0.30-0.47)$ & $2.4(2.0-2.9)$ & $5.4^{* *}(4.2-6.8)$ \\
\hline OH-MDZ/MDZ MR at $1 \mathrm{~h}$ & $0.47(0.37-0.58)$ & $0.21(0.17-0.27)$ & $0.45^{* *}(0.36-0.56)$ & $2.4(2.0-2.8)$ & $5.1^{* *}(4.2-6.3)$ \\
\hline OH-MDZ/MDZ MR at $2 \mathrm{~h}$ & $0.44(0.33-0.59)$ & $0.22(0.17-0.28)$ & $0.49^{* *}(0.38-0.65)$ & $2.6(2.2-3.0)$ & $6.0 * *(4.3-8.3)$ \\
\hline $\operatorname{MDZ~C}_{\max }(\mathrm{ng} / \mathrm{mL})$ & $3.1(2.3-4.2)$ & $11.7(9.2-14.9)$ & $3.7^{* *}(2.7-5.2)$ & $0.15(0.10-0.23)$ & $0.05^{* *}(0.03-0.07)$ \\
\hline
\end{tabular}

All data are presented as geometric means with $95 \%$ confidence intervals. AUC, area under the plasma concentration-time curve; $\mathrm{CL}$,

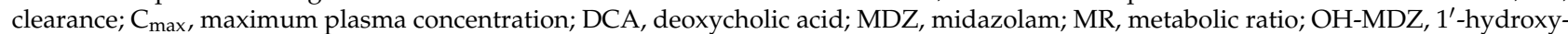
midazolam; UMR, urinary metabolic ratio; $1 \beta$-OH-DCA, $1 \beta$-hydroxy-deoxycholic acid. ${ }^{*} p<0.05 ;{ }^{* *} p<0.01$.

MDZ CL decreased significantly by $83 \%$ (inhibition ratio $=0.17$-fold, $95 \%$ confidence interval (CI) $0.13-0.22, p<0.01$ ) after the ingestion of CYP3A inhibitors. In the case of CYP3A induction by rifampicin, oral MDZ CL was significantly increased by 23.1-fold (95\% CI 17.3-30.7, $p<0.01$ ). The magnitude of drug-drug interactions (DDIs) was less pronounced when the metabolite OH-MDZ is taken into account. For instance, for OHMDZ/MDZ MR at $1 \mathrm{~h}$, we measured an inhibition ratio of 0.45 (95\% CI $0.36-0.56, p<0.01$ ) and an induction ratio of 5.1 (95\% CI 4.2-6.3, $p<0.01)$.

Based on in vitro evidence that DCA is a substrate for CYP3A4, the oral administration of CYP3A inhibitors is expected to decrease the UMR $1 \beta-\mathrm{OH}-\mathrm{DCA} / \mathrm{DCA}$. Such results were observed but were not significant, as shown in Figure 3 and Table 2 (inhibition ratio $=0.78$, $95 \%$ CI $0.52-1.2, p>0.05)$.
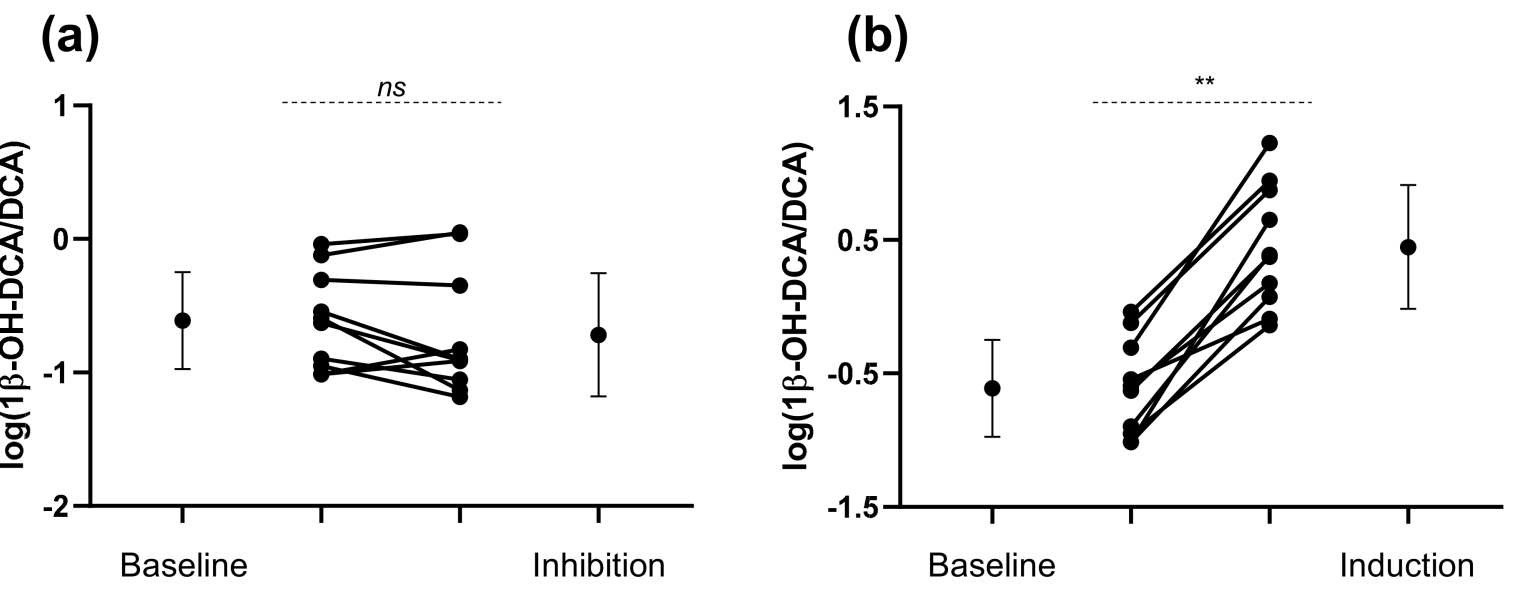

Figure 3. Eight-hour 1 $\beta$-hydroxy-deoxycholic acid/deoxycholic acid individual urinary metabolic ratios at baseline and after (a) the inhibition by voriconazole and fluvoxamine, and (b) induction by rifampicin. Error bars represent the standard deviations of log-transformed $1 \beta$-hydroxy-deoxycholic acid $(1 \beta-\mathrm{OH}-\mathrm{DCA} / \mathrm{DCA})$ and mean values are displayed with a circle. $1 \beta-O H-D C A / D C A, 1 \beta$-hydroxy-deoxycholic acid/deoxycholic acid. ${ }^{* *} p<0.01$

Similarly, fluvoxamine and voriconazole caused a non-significant decrease in $1 \beta-\mathrm{OH}-$ DCA urinary excretion of $38 \%$ (inhibition ratio $=0.62,95 \%$ CI $0.26-1.5, p>0.05$ ). However, the urinary excretion of DCA was not increased following CYP3A inhibition as theoretically expected (inhibition ratio $=0.79,95 \%$ CI $0.40-1.6, p>0.05$ ).

The endogenous ratio was 11.4-fold higher following rifampicin intake, a CYP3A inducer, compared to baseline (95\% CI 6.3-20.7, $p<0.01$ ) (Figure 3 and Table 2). 1 $\beta-\mathrm{OH}-$ 
DCA and DCA urinary excretion over $8 \mathrm{~h}$ were also significantly increased and decreased, respectively, during the CYP3A4 induction session, as described in Table 2.

\subsection{Correlations}

Table 3 shows the results regarding the Pearson's correlation coefficients between the log-transformed $1 \beta-O H-D C A / D C A$ UMR and the log-transformed MDZ metrics, including oral $\mathrm{CL}, \mathrm{C}_{\max }, \mathrm{AUClast}$ ratio, and MR at 1 and $2 \mathrm{~h}$, for each subject at baseline, after CYP3A inhibition, and after CYP3A induction (sessions measured combined or separately).

Table 3. Correlation of log-transformed urinary $1 \beta-O H-D C A / D C A$ ratio with log-transformed midazolam-based CYP3A4 metrics at baseline, after inhibition, and after induction.

\begin{tabular}{cccccccccc}
\hline & \multicolumn{2}{c}{ Baseline } & \multicolumn{2}{c}{ Inhibition } & \multicolumn{2}{c}{ Induction } & \multicolumn{2}{c}{ All Sessions } \\
\cline { 2 - 8 } & $\boldsymbol{r}$ & $\boldsymbol{p}$ & $\boldsymbol{r}$ & $\boldsymbol{p}$ & $\boldsymbol{r}$ & $\boldsymbol{p}$ & $\boldsymbol{r}$ & $\boldsymbol{p}$ \\
\hline Oral MDZ CL (L/h) & 0.652 & 0.041 & 0.336 & 0.343 & 0.678 & 0.031 & 0.808 & $<0.0001$ \\
\hline AUC $_{\mathbf{8}}$ OH-MDZ/AUC & $\mathbf{8}$ MDZ & 0.275 & 0.442 & 0.172 & 0.635 & 0.567 & 0.088 & 0.781 & $<0.0001$ \\
\hline OH-MDZ/MDZ MR at 1 h & 0.331 & 0.351 & -0.040 & 0.914 & 0.720 & 0.019 & 0.786 & $<0.0001$ \\
\hline OH-MDZ/MDZ MR at 2 h & 0.242 & 0.500 & 0.215 & 0.550 & 0.500 & 0.141 & 0.790 & $<0.0001$ \\
\hline MDZ C $_{\max }$ (ng/mL) & -0.652 & 0.041 & -0.491 & 0.150 & -0.456 & 0.185 & -0.821 & $<0.0001$ \\
\hline
\end{tabular}

AUC, area under the plasma concentration-time curve; $C L$, clearance; $C_{\max }$, maximum plasma concentration; DCA, deoxycholic acid; MDZ, midazolam; MR, metabolic ratio; OH-MDZ, 1'-hydroxy-midazolam; $1 \beta$-OH-DCA, $1 \beta$-hydroxy-deoxycholic acid.

Among them, the log-transformed oral MDZ CL and $\mathrm{C}_{\max }$ correlated significantly with the log-transformed 1 $\beta$-OH-DCA/DCA UMR at baseline $(r=0.652$ and $r=-0.652$, respectively, $p=0.041$ ). The log-transformed $1 \beta-\mathrm{OH}-\mathrm{DCA} / \mathrm{DCA}$ UMR correlated also significantly with the log-transformed MDZ CL and MR at $1 \mathrm{~h}$ after MDZ intake during the induction session $(r=0.678, p=0.031$ and $r=0.720, p=0.019$, respectively), whereas no significant correlations were found following inhibition. When taking into account all sessions simultaneously, the log-transformed $1 \beta$-OH-DCA/DCA UMR showed a significant correlation with all MDZ metrics $(p<0.0001)$.

Figure 4a shows the significant relationship between the log-transformed $1 \beta-\mathrm{OH}-$ DCA/DCA UMR and the log-transformed oral MDZ CL in participants at baseline only. Figure $4 \mathrm{~b}$ displays the significant correlation between the log-transformed $1 \beta-\mathrm{OH}-\mathrm{DCA} / \mathrm{DCA}$ UMR and the log-transformed oral MDZ CL in healthy volunteers at baseline, following inhibition with fluvoxamine/voriconazole and induction with rifampicin.

(a)

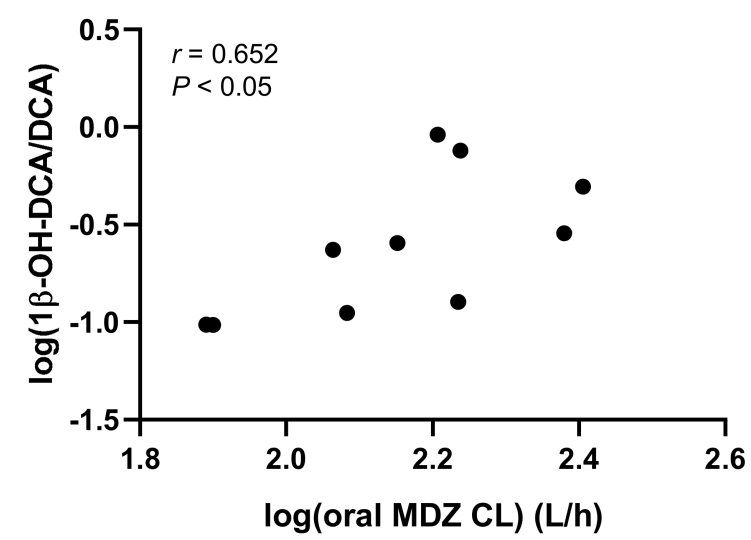

(b)

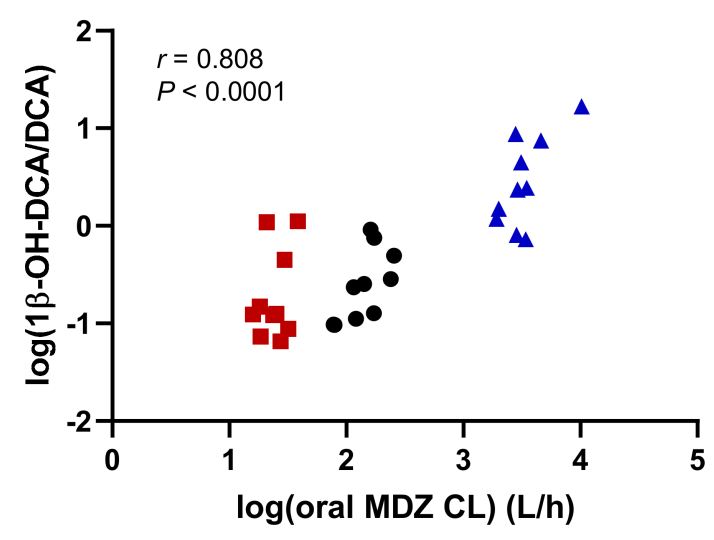

Figure 4. Correlation between log-transformed 1 $\beta$-hydroxy-deoxycholic acid/deoxycholic acid urinary metabolic ratio and oral midazolam clearance after (a) the administration of midazolam alone and after (b) the administration of midazolam alone and after pretreatment with voriconazole/fluvoxamine or rifampicin. Black circles, baseline; CYP3A4-inhibited phase, red square; CYP3A4-induced phase, blue triangles. 1 $\beta$-OH-DCA/DCA, 1 $\beta$-hydroxy-deoxycholic acid/deoxycholic acid; $\mathrm{CL}$, clearance; MDZ, midazolam. 


\section{Discussion}

\subsection{CYP3A Induction}

Following one week of treatment with $600 \mathrm{mg}$ of rifampicin, a significant 11.4-fold increase in the endogenous metric $1 \beta-\mathrm{OH}-\mathrm{DCA} / \mathrm{DCA}$ in human urine compared to baseline was observed. These results confirmed the observations made by Hayes et al. [21], who reported a 7-fold higher ratio in the urine of a carbamazepine-treated patient compared to a control sample. MDZ metrics were also effective in capturing changes in CYP3A activity among participants who received an inducer. For instance, oral MDZ CL and plasma OHMDZ/MDZ MR at $1 \mathrm{~h}$ were significantly increased by 23.1-fold and 5.1-fold, respectively, following rifampicin-mediated induction. The magnitude of CYP3A induction reflected by the endogenous $1 \beta-\mathrm{OH}-\mathrm{DCA} / \mathrm{DCA}$ UMR was lower compared to oral MDZ CL but higher than plasma 1-OH-MDZ/MDZ MR at $1 \mathrm{~h}$. The greater inter-individual variability observed in the endogenous UMR $1 \beta-\mathrm{OH}-\mathrm{DCA} / \mathrm{DCA}$ compared to MDZ metrics must be considered with caution and needs to be assessed in future studies with sufficient sample sizes. In particular, extrinsic and intrinsic factors potentially influencing this endogenous metric need to be investigated (e.g., circadian rhythm, pathological state, or fed/fasting conditions) [32-34]. The 6 $\beta$-hydroxycortisol/cortisol UMR is another common endogenous CYP3A metric with high inter-individual variability [35]. Shibasaki et al. [36] demonstrated that the inter-individual variability was lower when measuring the formation clearance $\left(\mathrm{CL}_{\mathrm{f}}\right)$ of $6 \beta$-hydroxycortisol compared to the UMR, which is likely affected by the variability in the renal CL of cortisol. Therefore, it may also be relevant to test the $\mathrm{CL}_{\mathrm{f}}$ of $1 \beta-\mathrm{OH}-\mathrm{DCA}$ from DCA in future studies.

Interestingly, even when analyzed individually, DCA and $1 \beta-\mathrm{OH}-\mathrm{DCA}$ showed significant down- and up-regulation, respectively, during the induction session. Such a pattern was not necessarily followed by other endogenous CYP3A substrates. For instance, plasma concentration of cholesterol, a CYP3A substrate metabolized into $4 \beta$-hydroxy-cholesterol, does not appear to decrease, as expected, upon drug induction [37,38]. In the research article of Kasichayanula et al. [38], the plasma concentration of cholesterol even showed a tendency to increase following the administration of rifampicin $600 \mathrm{mg}$ over two weeks. As a result, the ability of plasma $4 \beta-\mathrm{OH}$-cholesterol/cholesterol to highlight CYP3A induction may be weaker in comparison with other CYP3A4 metrics [16].

\subsection{CYP3A Inhibition}

Fluvoxamine, a moderate CYP3A inhibitor, was ingested $12 \mathrm{~h}$ and $2 \mathrm{~h}$ prior to MDZ administration, while voriconazole, a potent CYP3A inhibitor, was received as a single dose $2 \mathrm{~h}$ before MDZ administration $[39,40]$. No significant effect on the endogenous metric $1 \beta-\mathrm{OH}-\mathrm{DCA} / \mathrm{DCA}$ was observed following inhibitors intake. Urinary $1 \beta-\mathrm{OH}-\mathrm{DCA} / \mathrm{DCA}$ ratio and DCA excretion over $8 \mathrm{~h}$ were decreased by around $20 \%$ and urinary excretion of $1 \beta$-OH-DCA over $8 \mathrm{~h}$ was decreased by approximately $40 \%$ (all $p>0.05$ ). In contrast, MDZ CL decreased significantly by more than $80 \%$ following the intake of CYP450 inhibitors. Unlike exogenous probes ingested simultaneously with inhibitors, endogenous metabolites have baseline levels in urine and/or plasma at the time of inhibition. In that case, maximal capture of the inhibition would occur after at least four times the elimination half-life of the endogenous metabolite in order to fully eliminate baseline levels beforehand [41]. The elimination half-life of $1 \beta-\mathrm{OH}-\mathrm{DCA}$ is unknown, but it is likely that the CYP3A inhibition duration in this study ( $12 \mathrm{~h}$ ) is not long enough to measure significant changes in the $1 \beta-\mathrm{OH}-\mathrm{DCA} / \mathrm{DCA}$ UMR.

DCA excretion over $8 \mathrm{~h}$ was decreased (rather than increased as expected) following inhibitors intake, demonstrating the absence of impact of the modulation on this biomarker in this clinical trial. In this study, enzymatic hydrolysis was performed in order to deconjugate DCA and $1 \beta-\mathrm{OH}-\mathrm{DCA}$, including the predominant amidated conjugates using choloylglycine hydrolase. As performed by Hayes et al. [21], it might be relevant to evaluate whether chemical solvolysis to complete desulfation could help to adjust for these inconsistent results. 
Interestingly, in the manuscript of Shin et al. [37], the three endogenous CYP3A substrates cortisol, cortisone, and cholesterol were also illogically down-regulated during the inhibition session (ketoconazole $400 \mathrm{mg}$ once daily for four days) in both plasma and urine samples. Underlying mechanisms related to these observations are unclear. The decreased endogenous synthesis of these steroid hormones by the adrenal glands or increased metabolism may occur to compensate the CYP3A modulation [42,43]. Luo et al. [43] made the same observations regarding cortisol urinary excretion over $24 \mathrm{~h}$, which was not increased following the oral administration of clarithromycin $250 \mathrm{mg}$ twice daily for five days. In contrast, in the same study, the area under the concentration-time curve of plasma endogenous cortisol was significantly higher $(+19 \%, p=0.04)$ after CYP3A inhibition compared to baseline conditions, but there were no explanations for such discrepancies between plasma and urine [43]. Conversely, the endogenous metabolites, i.e., urinary $6 \beta$-hydroxy-cortisol, urinary $6 \beta$-hydroxy-cortisone, and plasma $4 \beta$-hydroxy-cholesterol, always seem to be consistently down-regulated during the inhibition phase $[16,37,43]$.

\subsection{Correlations}

In addition to providing a real-time snapshot of factors influencing the enzymatic pathway of interest (e.g., inhibition or induction), a probe must correlate with an exogenous reference probe drug [15]. In this clinical trial, the relationships between the urinary endogenous $1 \beta-\mathrm{OH}-\mathrm{DCA} / \mathrm{DCA}$ ratio and several MDZ metrics at baseline, after CYP3A inhibition, and after CYP3A induction were examined. Despite the small size of the study, the significant correlations observed at baseline with oral MDZ CL and $\mathrm{C}_{\max }$ are very promising. It indicates that the endogenous $1 \beta-\mathrm{OH}-\mathrm{DCA} / \mathrm{DCA} \mathrm{UMR}$ is a potential metric to phenotype CYP3A enzymes, which could possibly replace the need to administer MDZ. Moreover, Pearson's correlation coefficients were relatively high between the $1 \beta-\mathrm{OH}-\mathrm{DCA} / \mathrm{DCA}$ ratio and oral MDZ CL $(r=0.652, p=0.041)$ and $C_{\max }(r=-0.652, p=0.041)$, indicating a strong relationship. Interestingly, during the induction phase, significant correlations were also observed between the bile acid ratio and MDZ CL $(r=0.678, p=0.031)$, and MR at $1 \mathrm{~h}(r=0.720, p=0.019)$, showing a similar capacity to reflect CYP3A induction between the different metrics. Such correlations were not observed during the inhibition session, which is likely due to the lack of inhibitory effects observed on DCA and $1 \beta-O H-D C A$, as described previously, compared to MDZ. When data from control, inhibition, and induction sessions were used concomitantly, the log-transformed $1 \beta-\mathrm{OH}-\mathrm{DCA} / \mathrm{DCA}$ UMR correlated significantly with all MDZ metrics (all $p<0.0001$ ), confirming the ability of this endogenous marker to predict CYP3A activity when altered by DDIs, in particular CYP3A induction.

In most studies, the other endogenous metrics, e.g., urinary $6 \beta$-hydroxy-cortisol/cortisol ratio, showed no or weak correlation with MDZ metrics under basal conditions [15]. For instance, Luo et al. [43] demonstrated no correlation between urinary 6 $\beta$-hydroxycortisol/cortisol ratio and MDZ MR after oral administration (single dose of $7.5 \mathrm{mg}$ ) in 24 healthy volunteers. In the study by Lee et al. [18], the correlation between MDZ CL (measured after a single intravenous dose MDZ $1 \mathrm{mg}$ ) and $6 \beta$-hydroxy-cortisol/cortisol MR was significant but low (Pearson $r=0.278, p<0.01$ ) in 100 healthy subjects. Regarding plasma $4 \beta$-hydroxy-cholesterol, significant but relatively weak correlations have been described with MDZ CL at baseline, as summarized in two reviews dedicated to $4 \beta$-hydroxy-cholesterol $[16,44]$. Until recently, the highest correlation was reported by Tomalik-Scharte et al. [45], with Spearman's rank correlation coefficients of 0.348 observed between plasma $4 \beta$-hydroxy-cholesterol/cholesterol and MDZ CL after the intravenous administration of MDZ in 50 healthy volunteers. However, lately, a stronger correlation $(r=0.69)$ has been demonstrated between MDZ MR (single oral dose of $2 \mathrm{mg}$ ) and plasma $4 \beta$-hydroxy-cholesterol in 73 study participants (from a nondiabetic and diabetic population) [46].

Globally, correlations between endogenous and exogenous probes are subject to large discrepancies between the different studies. These differences can be related to many factors: the sample size used, the endogenous metric used (normalized versus 
not normalized, MR versus formation CL) and, very importantly, the exogenous metric used-in particular, its mode of administration (oral versus intravenous). Since intestinal and hepatic CYP3A activity are not correlated within the same subject, it is important to use the appropriate probe according what needs to be characterized. In the case of exogenous probes, oral probes will be used to reflect hepatic and intestinal activity, and an intravenous probe will be used to reflect hepatic activity only [16,44]. As described by Penzak et al. [44], endogenous biomarkers represent unusual probes because it is not known whether they can reflect intestinal metabolism, as they are not administered either orally or intravenously. Some authors assumed that endogenous CYP3A markers will only phenotype hepatic activity, and for these reasons, they used intravenous MDZ to establish correlations [17]. However, as most of the drugs are administered orally, we believe that an ideal endogenous probe should also reflect CYP3A intestinal metabolism. In this context, bile acids are promising CYP3A biomarkers, since they are actively reabsorbed in the distal ileum by the apical sodium-dependent bile acid transporter [47]. DCA is a secondary bile acid produced through 7-dehydroxylation by gut bacteria of cholic acid (CA), which is a primary bile acid synthesized from cholesterol into the liver [22]. Then, DCA is likely recycled in the enterohepatic system, where its biotransformation into the tertiary bile acid $1 \beta-\mathrm{OH}-\mathrm{DCA}$ may occur via intestinal and hepatic CYP3A [23]. Thus, it appears appropriate to correlate the urinary $1 \beta-\mathrm{OH}-\mathrm{DCA} / \mathrm{DCA}$ ratio with $\mathrm{MDZ}$ metrics measured after oral administration of MDZ (rather than intravenous administration).

\section{Conclusions}

In this clinical trial, we assessed the suitability of two bile acids, DCA and its metabolite $1 \beta-\mathrm{OH}-\mathrm{DCA}$, to substitute MDZ in order to predict CYP3A activity. Indeed, sub-therapeutic doses of oral MDZ (1 mg), as used in this clinical trial, help to avoid possible adverse effects, but phenotyping using exogenous probes still involves cost, reconditioning, and/or manufacturing (and therefore, a risk of error). In addition, the administration of nontherapeutic probe drugs can cause ethical challenges in vulnerable individuals, such as pregnant women or children [48]. For these reasons, the use of an endogenous marker to phenotype CYP3A activity appears more convenient.

In this study, additional clinical data were provided for the urinary endogenous $1 \beta$ $\mathrm{OH}-\mathrm{DCA} / \mathrm{DCA}$ ratio, which is a promising metric for CYP3A phenotyping first evidenced by Bodin et al. [20] a few years ago. Significant correlations were obtained between the urinary $1 \beta-\mathrm{OH}-\mathrm{DCA} / \mathrm{DCA}$ ratio and some MDZ metrics at baseline and after induction.

This biomarker can also accurately detect changes in CYP3A activity due to enzyme induction by rifampicin in ten healthy male volunteers. In contrast, we believe that CYP3A inhibitors were not administered long enough to demonstrate significant changes in the urinary bile acids levels. Further studies are needed in this regard to validate the use of the $1 \beta-O H-D C A / D C A$ couple as an endogenous CYP3A probe. Comparison with other endogenous CYP3A probes may also be relevant to study in larger sample sizes. Potentially, a combination with other endogenous CYP3A probes may be considered to improve the prediction of enzyme activity using multivariate models. Additional investigations appear also required to understand in more detail the role of intestinal CYP3A in the metabolism of DCA. The limitations of the current study are that only male volunteers were included and that subjects were not genotyped for CYP3A4 and CYP3A5 enzymes. Genotyping was considered irrelevant due to the small sample size and low frequency of the alleles of interest in the Caucasian population (e.g., CYP3A4*22 and CYP3A5*1) [49]. In a previous study including forty-two healthy volunteers, we observed non-significant differences in the 1 $\beta-O H-D C A / D C A$ UMR between the CYP3A poor, intermediate, and extensive metabolizers (manuscript submitted for publication). In vitro, CYP3A5 appears also minimally involved in the hydroxylation of DCA [21]. Therefore, it seems important to study this pathway in larger in vivo study cohorts to determine whether this endogenous biomarker can serve as a selective probe for CYP3A4 phenotyping or whether it is a CYP3A endogenous probe. 
Author Contributions: G.M. wrote the manuscript, revised by all the authors; G.M., M.B., J.D., and Y.D. designed the research; G.M., M.B., and Y.D. performed the research; G.M., M.B., and Y.D. analyzed the data; A.T. contributed new reagents/analytical tools. All authors have read and agreed to the published version of the manuscript.

Funding: This research received no external funding.

Institutional Review Board Statement: The study was conducted according to the guidelines of the Declaration of Helsinki, and approved by the Geneva Research Ethics Committee (12-085) as well as the Swiss Agency for Therapeutic Drugs (Swissmedic) (2012DR1197). Further use of the data and samples was approved by the Geneva Research Ethics Committee (2020-02424).

Informed Consent Statement: Informed consent was obtained from all subjects involved in the study.

Data Availability Statement: The data presented in this study are available on request from the corresponding author.

Acknowledgments: The authors would like to thank the Clinical Research Center of Geneva University Hospital for helpful contribution. This work was supported by the Department of Anesthesiology, Clinical Pharmacology, Intensive Care and Emergency Medicine of the Geneva University Hospitals.

Conflicts of Interest: The authors declare no conflict of interest.

\section{References}

1. Zanger, U.M.; Schwab, M. Cytochrome P450 Enzymes in Drug Metabolism: Regulation of Gene Expression, Enzyme Activities, and Impact of Genetic Variation. Pharmacol. Ther. 2013, 138, 103-141. [CrossRef]

2. Tracy, T.S.; Chaudhry, A.S.; Prasad, B.; Thummel, K.E.; Schuetz, E.G.; Zhong, X.; Tien, Y.-C.; Jeong, H.; Pan, X.; Shireman, L.M.; et al. Interindividual Variability in Cytochrome P450-Mediated Drug Metabolism. Drug Metab. Dispos. 2016, 44, 343-351. [CrossRef] [PubMed]

3. Wang, D.; Sadee, W. The Making of a CYP3A Biomarker Panel for Guiding Drug Therapy. J. Pers. Med. 2012, 2, 175-191. [CrossRef]

4. Yang, L.; Price, E.T.; Chang, C.-W.; Li, Y.; Huang, Y.; Guo, L.-W.; Guo, Y.; Kaput, J.; Shi, L.; Ning, B. Gene Expression Variability in Human Hepatic Drug Metabolizing Enzymes and Transporters. PLoS ONE 2013, 8, e60368. [CrossRef] [PubMed]

5. Samer, C.F.; Lorenzini, K.I.; Rollason, V.; Daali, Y.; Desmeules, J.A. Applications of CYP450 Testing in the Clinical Setting. Mol. Diagn. Ther. 2013, 17, 165-184. [CrossRef] [PubMed]

6. Hu, M.; Mak, V.W.L.; Tomlinson, B. Simvastatin-Induced Myopathy, the Role of Interaction with Diltiazem and Genetic Predisposition. J. Clin. Pharm. 2011, 36, 419-425. [CrossRef]

7. Lee, A.J.; Maddix, D.S. Rhabdomyolysis Secondary to a Drug Interaction between Simvastatin and Clarithromycin. Ann. Pharm. 2001, 35, 26-31. [CrossRef]

8. Marot, A.; Morelle, J.; Chouinard, V.A.; Jadoul, M.; Lambert, M.; Demoulin, N. Concomitant Use of Simvastatin and Amiodarone Resulting in Severe Rhabdomyolysis: A Case Report and Review of the Literature. Acta Clin. Belg. 2011, 66, 134-136. [CrossRef]

9. McGraw, J.; Gerhardt, A.; Morris, T.C. Opportunities and Obstacles in Genotypic Prediction of Cytochrome P450 Phenotypes. Expert Opin. Drug Metab. Toxicol. 2018, 14, 659-661. [CrossRef]

10. Miao, J.; Jin, Y.; Marunde, R.L.; Kim, S.; Quinney, S.; Radovich, M.; Li, L.; Hall, S.D. Association of Genotypes of the CYP3A Cluster with Midazolam Disposition In Vivo. Pharm. J. 2009, 9, 319. [CrossRef]

11. Kurnik, D.; Wood, A.J.J.; Wilkinson, G.R. The Erythromycin Breath Test Reflects P-Glycoprotein Function Independently of Cytochrome P450 3A Activity. Clin. Pharmacol. Ther. 2006, 80, 228-234. [CrossRef]

12. Sugiyama, E.; Kikuchi, A.; Inada, M.; Sato, H. The Use of 13C-Erythromycin as an in Vivo Probe to Evaluate CYP3A-Mediated Drug Interactions in Rats. J. Pharm. Sci. 2011, 100, 3995-4005. [CrossRef] [PubMed]

13. Christians, U.; Schmitz, V.; Haschke, M. Functional Interactions between P-Glycoprotein and CYP3A in Drug Metabolism. Expert Opin. Drug Metab. Toxicol. 2005, 1, 641-654. [CrossRef] [PubMed]

14. Rollason, V.; Mouterde, M.; Daali, Y.; Čížková, M.; Priehodová, E.; Kulichová, I.; Posová, H.; Petanová, J.; Mulugeta, A.; Makonnen, E.; et al. Safety of the Geneva Cocktail, a Cytochrome P450 and P-Glycoprotein Phenotyping Cocktail, in Healthy Volunteers from Three Different Geographic Origins. Drug Saf. 2020, 43, 1181-1189. [CrossRef]

15. Magliocco, G.; Thomas, A.; Desmeules, J.; Daali, Y. Phenotyping of Human CYP450 Enzymes by Endobiotics: Current Knowledge and Methodological Approaches. Clin. Pharm. 2019, 58, 1373-1391. [CrossRef] [PubMed]

16. Mao, J.; Martin, I.; McLeod, J.; Nolan, G.; van Horn, R.; Vourvahis, M.; Lin, Y.S. Perspective: $4 \beta$-Hydroxycholesterol as an Emerging Endogenous Biomarker of Hepatic CYP3A. Drug Metab. Rev. 2017, 49, 18-34. [CrossRef] [PubMed]

17. Kim, B.; Lee, J.; Shin, K.-H.; Lee, S.; Yu, K.-S.; Jang, I.-J.; Cho, J.-Y. Identification of $\omega$ - or ( $\omega$-1)-Hydroxylated Medium-Chain Acylcarnitines as Novel Urinary Biomarkers for CYP3A Activity. Clin. Pharmacol. Ther. 2018, 103, 879-887. [CrossRef]

18. Lee, J.; Kim, A.H.; Yi, S.; Lee, S.; Yoon, S.H.; Yu, K.-S.; Jang, I.-J.; Cho, J.-Y. Distribution of Exogenous and Endogenous CYP3A Markers and Related Factors in Healthy Males and Females. AAPS J 2017, 19, 1196-1204. [CrossRef] 
19. Chen, J.; Zhao, K.-N.; Chen, C. The Role of CYP3A4 in the Biotransformation of Bile Acids and Therapeutic Implication for Cholestasis. Ann. Transl. Med. 2014, 2. [CrossRef]

20. Bodin, K.; Lindbom, U.; Diczfalusy, U. Novel Pathways of Bile Acid Metabolism Involving CYP3A4. Biochim. Biophys. Acta 2005, 1687, 84-93. [CrossRef]

21. Hayes, M.A.; Li, X.-Q.; Grönberg, G.; Diczfalusy, U.; Andersson, T.B. CYP3A Specifically Catalyzes 1 $\beta$-Hydroxylation of Deoxycholic Acid: Characterization and Enzymatic Synthesis of a Potential Novel Urinary Biomarker for CYP3A Activity. Drug Metab. Dispos. 2016, 44, 1480-1489. [CrossRef]

22. Chen, Y.-J.; Zhang, J.; Zhu, P.-P.; Tan, X.-W.; Lin, Q.-H.; Wang, W.-X.; Yin, S.-S.; Gao, L.-Z.; Su, M.-M.; Liu, C.-X.; et al. Stereoselective Oxidation Kinetics of Deoxycholate in Recombinant and Microsomal CYP3A Enzymes: Deoxycholate 19-Hydroxylation Is an In Vitro Marker of CYP3A7 Activity. Drug Metab. Dispos. 2019, 47, 574-581. [CrossRef]

23. Zhang, J.; Gao, L.-Z.; Chen, Y.-J.; Zhu, P.-P.; Yin, S.-S.; Su, M.-M.; Ni, Y.; Miao, J.; Wu, W.-L.; Chen, H.; et al. Continuum of Host-Gut Microbial Co-Metabolism: Host CYP3A4/3A7 Are Responsible for Tertiary Oxidations of Deoxycholate Species. Drug Metab. Dispos. 2019, 47, 283-294. [CrossRef] [PubMed]

24. Bosilkovska, M.; Samer, C.F.; Déglon, J.; Rebsamen, M.; Staub, C.; Dayer, P.; Walder, B.; Desmeules, J.A.; Daali, Y. Geneva Cocktail for Cytochrome P450 and P-Glycoprotein Activity Assessment Using Dried Blood Spots. Clin. Pharmacol. Ther. 2014, 96, 349-359. [CrossRef] [PubMed]

25. Bosilkovska, M.; Déglon, J.; Samer, C.; Walder, B.; Desmeules, J.; Staub, C.; Daali, Y. Simultaneous LC-MS/MS Quantification of P-Glycoprotein and Cytochrome P450 Probe Substrates and Their Metabolites in DBS and Plasma. Bioanalysis 2014, 6, 151-164. [CrossRef] [PubMed]

26. Cook, J.D.; Strauss, K.A.; Caplan, Y.H.; LoDico, C.P.; Bush, D.M. Urine PH: The Effects of Time and Temperature after Collection. J. Anal. Toxicol. 2007, 31, 486-496. [CrossRef]

27. Thakare, R.; Chhonker, Y.S.; Gautam, N.; Alamoudi, J.A.; Alnouti, Y. Quantitative Analysis of Endogenous Compounds. J. Pharm. Biomed. Anal. 2016, 128, 426-437. [CrossRef] [PubMed]

28. Sarafian, M.H.; Lewis, M.R.; Pechlivanis, A.; Ralphs, S.; McPhail, M.J.W.; Patel, V.C.; Dumas, M.-E.; Holmes, E.; Nicholson, J.K. Bile Acid Profiling and Quantification in Biofluids Using Ultra-Performance Liquid Chromatography Tandem Mass Spectrometry. Anal. Chem. 2015, 87, 9662-9670. [CrossRef]

29. Scherer, M.; Gnewuch, C.; Schmitz, G.; Liebisch, G. Rapid Quantification of Bile Acids and Their Conjugates in Serum by Liquid Chromatography-Tandem Mass Spectrometry. J. Chromatogr. B Anal. Technol. Biomed. Life Sci. 2009, 877, 3920-3925. [CrossRef]

30. Ulaszewska, M.M.; Mancini, A.; Garcia-Aloy, M.; Del Bubba, M.; Tuohy, K.M.; Vrhovsek, U. Isotopic Dilution Method for Bile Acid Profiling Reveals New Sulfate Glycine-Conjugated Dihydroxy Bile Acids and Glucuronide Bile Acids in Serum. J. Pharm. Biomed. Anal. 2019, 173, 1-17. [CrossRef]

31. Kanebratt, K.P.; Diczfalusy, U.; Bäckström, T.; Sparve, E.; Bredberg, E.; Böttiger, Y.; Andersson, T.B.; Bertilsson, L. Cytochrome P450 Induction by Rifampicin in Healthy Subjects: Determination Using the Karolinska Cocktail and the Endogenous CYP3A4 Marker 4 $\beta$-Hydroxycholesterol. Clin. Pharmacol. Ther. 2008, 84, 589-594. [CrossRef] [PubMed]

32. Yang, Y.; Zhang, J. Bile Acid Metabolism and Circadian Rhythms. Am. J. Physiol. Gastrointest. Liver Physiol. 2020, 319, G549-G563. [CrossRef]

33. Li, T.; Apte, U. Bile Acid Metabolism and Signaling in Cholestasis, Inflammation and Cancer. Adv. Pharm. 2015, 74, 263-302. [CrossRef]

34. Setchell, K.D.; Lawson, A.M.; Blackstock, E.J.; Murphy, G.M. Diurnal Changes in Serum Unconjugated Bile Acids in Normal Man. Gut 1982, 23, 637-642. [CrossRef]

35. Galteau, M.M.; Shamsa, F. Urinary 6beta-Hydroxycortisol: A Validated Test for Evaluating Drug Induction or Drug Inhibition Mediated through CYP3A in Humans and in Animals. Eur. J. Clin. Pharmacol. 2003, 59, 713-733. [CrossRef]

36. Shibasaki, H.; Hosoda, K.; Goto, M.; Suzuki, A.; Yokokawa, A.; Ishii, K.; Furuta, T. Intraindividual and Interindividual Variabilities in Endogenous Cortisol 6ß-Hydroxylation Clearance as an Index for in Vivo CYP3A Phenotyping in Humans. Drug Metab. Dispos. 2013, 41, 475-479. [CrossRef] [PubMed]

37. Shin, K.-H.; Choi, M.H.; Lim, K.S.; Yu, K.-S.; Jang, I.-J.; Cho, J.-Y. Evaluation of Endogenous Metabolic Markers of Hepatic CYP3A Activity Using Metabolic Profiling and Midazolam Clearance. Clin. Pharmacol. Ther. 2013, 94, 601-609. [CrossRef] [PubMed]

38. Kasichayanula, S.; Boulton, D.W.; Luo, W.-L.; Rodrigues, A.D.; Yang, Z.; Goodenough, A.; Lee, M.; Jemal, M.; LaCreta, F. Validation of $4 \beta$-Hydroxycholesterol and Evaluation of Other Endogenous Biomarkers for the Assessment of CYP3A Activity in Healthy Subjects. Br. J. Clin. Pharm. 2014, 78, 1122-1134. [CrossRef] [PubMed]

39. Hemeryck, A.; Belpaire, F.M. Selective Serotonin Reuptake Inhibitors and Cytochrome P-450 Mediated Drug-Drug Interactions: An Update. Curr. Drug Metab. 2002, 3, 13-37. [CrossRef]

40. Saari, T.I.; Laine, K.; Leino, K.; Valtonen, M.; Neuvonen, P.J.; Olkkola, K.T. Effect of Voriconazole on the Pharmacokinetics and Pharmacodynamics of Intravenous and Oral Midazolam. Clin. Pharm. Ther. 2006, 79, 362-370. [CrossRef]

41. Greenblatt, D.J. Elimination Half-Life of Drugs: Value and Limitations. Annu. Rev. Med. 1985, 36, 421-427. [CrossRef] [PubMed]

42. Taves, M.D.; Gomez-Sanchez, C.E.; Soma, K.K. Extra-Adrenal Glucocorticoids and Mineralocorticoids: Evidence for Local Synthesis, Regulation, and Function. Am. J. Physiol. Endocrinol. Metab. 2011, 301, E11-E24. [CrossRef]

43. Luo, X.; Li, X.; Hu, Z.; Cheng, Z. Evaluation of CYP3A Activity in Humans Using Three Different Parameters Based on Endogenous Cortisol Metabolism. Acta Pharmacol. Sin. 2009, 30, 1323-1329. [CrossRef] [PubMed] 
44. Penzak, S.R.; Rojas-Fernandez, C. 4 $\beta$-Hydroxycholesterol as an Endogenous Biomarker for CYP3A Activity: Literature Review and Critical Evaluation. J. Clin. Pharmacol. 2019, 59, 611-624. [CrossRef]

45. Tomalik-Scharte, D.; Lütjohann, D.; Doroshyenko, O.; Frank, D.; Jetter, A.; Fuhr, U. Plasma 4beta-Hydroxycholesterol: An Endogenous CYP3A Metric? Clin. Pharmacol. Ther. 2009, 86, 147-153. [CrossRef] [PubMed]

46. Gravel, S.; Chiasson, J.-L.; Gaudette, F.; Turgeon, J.; Michaud, V. Use of 4 $\beta$-Hydroxycholesterol Plasma Concentrations as an Endogenous Biomarker of CYP3A Activity: Clinical Validation in Individuals With Type 2 Diabetes. Clin. Pharmacol. Ther. 2019, 106, 831-840. [CrossRef]

47. Ticho, A.L.; Malhotra, P.; Dudeja, P.K.; Gill, R.K.; Alrefai, W.A. Intestinal Absorption of Bile Acids in Health and Disease. Compr. Physiol. 2019, 10, 21-56. [CrossRef]

48. de Wildt, S.N.; Ito, S.; Koren, G. Challenges for Drug Studies in Children: CYP3A Phenotyping as Example. Drug Discov. Today 2009, 14, 6-15. [CrossRef]

49. Elens, L.; van Gelder, T.; Hesselink, D.A.; Haufroid, V.; van Schaik, R.H.N. CYP3A4*22: Promising Newly Identified CYP3A4 Variant Allele for Personalizing Pharmacotherapy. Pharmacogenomics 2013, 14, 47-62. [CrossRef] 